\title{
Impacts of the Demonstration Method in the Teaching and Learning of Hearing Impaired Children.
}

\author{
Chingombe Shamiso Iline \\ Educational Foundations Department: Great Zimbabwe University: Zimbabwe
}

\begin{abstract}
The purpose of this research was to study the effectiveness of the demonstration teaching method in the teaching of the hearing impaired at a special school in Harare province in Zimbabwe. The research focus was on whether the demonstration should be augmented with other teaching methods. Focus was also on whether the teachers were knowledgeable about the demonstration method and if the resources were adequately channeled and used. A case study based on qualitative paradigm was used in this research. A sample of three teachers, ten pupils the school head and the head of department for technical subjects were used. For the purpose of triangulation, instruments used included interviews, observations, questionnaires and document analysis. The research findings revealed that the demonstration method was not effectively used. For lack of individualized Plan, the pupils did not benefit much from the lessons. The use of sign language was not properly implemented, yet there is need for collaborative use of both sign and oral language. The need for adequate resources for the hearing impaired, also featured prominently in the research findings in order for pupils to work at their own pace.
\end{abstract}

Keywords: Individualised Educational Plan, institutionalised: case study, impacts, demonstration, deaf,

\section{Introduction and Background}

Children with hearing impairment differ from the "normal" ones in that they have a disability in hearing and talking. Hallahan and Kauffman (1984) refer to the hearing impairment as the deaf, describing the disability and the way through which hearing impairment children should learn. Smart (1998) states that the deaf have a restriction to communicate and this make them different from other people. That is, they do not have a gift of verbal communication shared by the 'normal' people. He further propounds that the difference should determine the ways the students should be taught. This means that, similar methods cannot be used for both the hearing impaired and the 'normal' children. They may be taught educational concepts using similar methods but care should be taken that they are applied to suit the needs of the learners. As such, demonstration method is a method that is suitable for most categories of learners.

According to Smith (1998), demonstration must be used in a manner that suits the needs of the hearing impaired children. For correct use of the methods to be realized, teachers need to be knowledgeable about the special learning needs of the hearing impaired children. Contrary to the view Chiswanda in Chimedza and Peters (1994) indicates that most teachers who are teaching the hearing impaired children have not acquired special education, neither do they know how to use sign language effectively in their teaching. This implies that, the use of teaching methods may not be effective as unknowledgeable teachers use them. The study therefore sought to investigate and establish effectiveness of the demonstration method in the teaching of garment construction to the hearing impared.

\section{Statement of the problem}

The researcher has always been wandering why the hearing impaired students were performing quite well in practical subjects as compared to all other academic subjects. It was only after taking a course in Special Needs Education that there was enlightment that learners with disabilities have special needs, regarding their teaching and learning. This therefore prompted the desire to investigate how the demonstration method was used in teaching and learning of to the hearing impaired pupils.

\section{Research questions}

The following research questions were intended to guide the study:

$>$ Are the teachers knowledgeable about the use of the demonstration method to teach the hearing impaired children?

$>$ Is there need to augment or integrate the demonstration method with other teaching methods?

$>$ Does the school have adequate resources for the teacher to use during the teaching and learning of the hearing impaired pupils 


\section{Conceptual Framework}

The methods which are applied to the hearing impaired children are similar to those used to the 'normal' pupils. Chimedza and Peterson (2003) postulated that the methods used and content are similar because there is no special examination for the hearing impaired children. However, UNESCO (1995) states that pupils with disabilities should be awarded an extra thirty minutes during the examination to compensate for their disability. The hearing impaired pupils need special attention from the teacher.

Good and Brophy (1987) highlight that, the materials and procedures should permit child to progress at a pace best suited to his or her disability and interests. They were, thus, advocating for Individualised Educational Plan (IEP). This is in harmony with Louis and Manion (1997) who are of the view that IEP enables the child to work at a pace best suited for his or her needs and ability. The child will, therefore, not be stretched beyond his or her capabilities. Hearing impaired is an umbrella term includes hard of hearing and the deaf. Meyen (1996) describes hard of hearing as pupils who have hearing loss but have both speech and language. Hallahan and Kauffman (1984) describe the deaf as pupils who have lost both speech and hearing. Thus, teachers need to employ teaching and learning methods that would cater for both the deaf and the hard of hearing pupils.

\section{Individualised Educational Plan}

The IEP process is part of good teaching and learning. It acknowledges areas of individual needs and capacity of all children to learn (Gross 1993). It refers to both the ongoing process and the associated documentation that informs the education of a student with special and additional needs through describing, documentation, monitoring and evaluating the students' educational needs, support and outcomes (Steere and Cavainolo 2002).

An IEP is tailor made to meet the unique educational needs for one child. Wiggins and McTtighe 2001) state that the IEP must be designed to the individual student needs, identified by the evaluation process and must help the teachers and related service providers understand the student and how best to work with him or her. In other words, the IEP should describe how the student learns and how best the student would be expected or required to demonstrate that learning is effectively taking place. Covey (1996) outlined that under no circumstances should an IEP be written to fit a particular placement. He went on to say that services for each student must be individually considered and recommended and should not depend upon known or existing services. He suggested that each IEP must be designed to meet specific needs of one student and must be truly individualized document. According to Chikuni (2003) individualized learning generally means a one to one teaching / learning process. She further explained that each child with a handicap requires to be dealt with as an individual if any learning is to take place. To reinforce the one to one basis, Chimedza and Peterson (2003) affirms that, the teacher pupil ratio of the hearing impaired pupils is one as to seven (1:7). Thus according to Obanya (1980), individualised educational plan (IEP) would meet the need of each child if the recommended teacher pupil ratio is observed. The importance placed on IEP promotes the desire to establish if teachers use individualised instruction in their teaching.

\section{Teaching methods.}

There are various methods of teaching and the choice of teaching methods/s to use is affected by many components such as content, time, ability of pupils, group size as well as the teachers' personal preference (Andrusyzyn 1990). Mutasa and Wills (1995) propound that the demonstration method involves the teacher showing pupils how to do something while they observe. Pupils' practice will follow the teachers' demonstrations. According to Chamberlain and Kelly (1981) demonstrations are used to show procedures and to explained techniques. Thus, demonstration is a direct means of explaining things to the pupils. Chikuni (2003) also states that demonstration is where the teacher shows how something is done by actually doing it. According to Child (1988), a child learns better through imitating. Kudu and Tutoo (2002) concur with Child when they state that Banduras' bobo doll experiment showed that children learn through imitation. In support of this, Hendrik (1986) figured out that children learn vicariously through emulation. Therefore the demonstrations ought to be done correctly for pupils to copy the correct ways of doing things. For Gwarinda ( 1993),demonstration method enhances translation of theory into practice. Soroka, Hoagland and Mohale (1977) propound that the demonstration method should be used to impart skills. That is why this method is often opted in the teaching and learning of practical subjects.

Gwarinda (1993) concurs with Soroka, Hoagland and Mohale (1977) who affirm that demonstration involves teaching pupils how a specific skill is executed. This method is recommended for teaching a skill because it enables covering of all the necessary steps in a process (Petty 200). Thus, the demonstration method gives pupils the opportunity to see and hear the details related being taught. These details include the necessary background knowledge, steps or procedures precautions (McKeachie 1986). The demonstration gives pupils the 
opportunity to become proficient. In short, this method is recommended because it leaves nothing to chance. Various demonstration techniques are used to impart skills to learners.

\section{Types of demonstration}

It has been propounded by Chikuni (2003) that, there are two types of demonstrations, namely the step by step and the whole process demonstration. In the whole process demonstration, the teacher demonstrates the full process from the beginning to the end without interruption by learners' participation (Chikuni 2003). For instance, the teacher shows how to tack the dart, stitch it, and fasten the thread and pressing the dart to the correct side. The pupils will then follow the process by making their darts. Soroka, Hoagland and Mohale (1977) assert that the whole process demonstration enables the pupils to have a clear view of the process.

For Gwarinda (1993) the step by step demonstration is done stage by stage with teacher explaining each action as the operation proceeds. Chikuni (2003) also notes that the step by step demonstration takes place when the process is presented in stages that are inter- spaced by learners' participation. For example, when making a shirt, the teacher demonstrates how to attach a patch pocket and pupils work on their shirts individually, after the demonstration. The teacher will then demonstrate how to work the seams and pupils follow suit until all the processes are completed. This is probably one of the ways of demonstrating as it caters for different learning abilities (Chikuni 2003). This method is ideal for hearing impaired pupils because they can understand better as too many ideas at the same times may confuse them. In recognition of this procedure, Bandura in Santrock (1997) affirms that the children learn effectively through immediate imitation. More - so, the method is also ideal for the hearing impaired pupils for they would produce what had been demonstrated whilst it is still fresh in their minds. Chikuni (2003) emphasizes that for convenience the techniques for imparting skills are presented in steps.

In addition to Chikuni's (2003) two types of demonstrations, McKeachie (1986) suggests the spot demonstrations, which is usually done after the teacher identifies a problem or a mistake being made by the pupils. This is done after the procedure has been shown before. For Petty (2000), if the teacher spots a problem, pupils will then be stopped and the teacher will redemonstrate the skill. This strategy helps to prevent worsening of the problem.

\section{General hints on how demonstration is done}

According to Chikuni (2003), the demonstration method should be prepared thoroughly to avoid any kind of error, as it may be difficult to correct. Gatawa (1994) suggests that when demonstrating, the teacher must explain the reason for the significance of each step. For the demonstration to be effective, the teacher must plan it prior to the lesson. This is to ensure that all necessary steps are sequentially arranged (Chamberlain and Kelly 1981). This is done to eradicate omission of necessary procedures in making a procedure. However, Kim and Kellough (1995) propose that the teacher should involve the pupils when demonstrating. Involvement can be through asking questions where there are not clear or through demonstrating figures which have been shown before (Kasambira (1993). Gwarida (1993 suggest that, teachers need to redemonstrate where pupils are failing to reproduce the skills shown before.

During demonstration, Gwarinda (1993) recommends the use of educational aids where necessary. For example, a photographic media can be used to show the appearance of a completed item. This may be essential for instilling an idea of what the taught process leads to. Field trips can also be augmented with the demonstration method in imparting skills to the pupils. They involve pupils learning outside the classroom situation. Gall, Borg and Gall (1996) state that, pupils gain first hand experience of work procedures and conditions through field trips. This concurs with Obanya (1980) who describes field trips as useful trips for learning that may help pupils to obtain firsthand experience of objects and situations. Thus, field trip enhances concretization of learning and promotes understanding. Chamberlain and Kelly (1981) pointed out that field trips are informative.

Apart from field trips, discussion method can also be augmented the demonstration method during the teaching and learning by grouping pupils to solve a given task. Siyakwazi and Siyakwazi (1989) propound that the discussion method permits a greater degree of cooperation amongst the learners. Discussion promotes communication and exchange of ideas among students. Chamberlain and Kelly (1981) note that, students who are reluctant to participate when in larger groups, often participate in smaller groups. Mills (1991) supports this fact by stating that shy students who do not contribute in a full class can usually be coaxed into contributing during discussions. Fraser, Loubser and Roy (1990) in Siyakwazi and Siyakwazi (1999) observed that there is less spoon feeding in this method. Pupils will be free to make some contributions during their learning processes. In addition, they say that pupils' views will be respected. This will be done through the use of sign language for effective group discussions to be realized. Mutasa and Wills (1995) suggest that the teacher should select the groups for discussion. In support of this, Dean (1996) opted for the teacher selected groups as a strategy of minimizing chances of learners drifting away from the effective learning exercises. Moreover 
Gatawa (1993) emphasises that the teachers are required to supervise pupils during group work for effective discussions to take place.

The lecture method is one of the most common teaching strategies (Siyakwazi and Siyakwazi 1999). Weaver in Andrusyzn (1990) advised that effective lecture requires a large degree of preparation and expertise and it is not ease to accomplish. She says that, an accomplished lecture is able to explain things clearly, is organized, stimulative and is full of enthusiasm. The procedures need to be sequentially arranged.

Obanya (1980) outlines that the lecture method is used to practical subjects requiring the teachers' exposition, for instance, when there is need to correct or explain how a process is done. For Jones (1990), the lecture method is still one of the most effective ways of providing information to students as long as it is clearly presented and uses the full range of techniques and visual aids available. However, it can be argued that, the lecture method puts the learners into a passive role.

\section{Teachers' knowledge}

Chamberlain and Kelly (1981) note that a knowledgeable teacher is the one who is able to vary instructional strategies. These may include group discussion, lecture method and demonstration method. In view of this, Zvobgo (1990) outlines that teachers should be able to meet individual educational needs of their pupils. Pupils should be treated as unique individuals. Siyakwazi and Siyakwazi (1999) point out that, in order for the teachers to be considered competent in a subject, they must have a deep understanding of the teaching area and should have received special training. Teachers need to have the subject matter at their finger tips. Chikuni (2003) points out that a knowledgeable teacher is one who has a full understanding of learning style for each of the learners' style or modes of presentation so that the methods to be used will cater for individual differences. Linhard, Dlamini and Bernard (1985:13) state that, the teacher should, 'teach from the known to the unknown.' That is, teaching should progress from what is commonly known by the learner to something that is new and challenging. For example, when teaching students something new, the teacher should start by referring to something new, the teacher should start by referring to something they already know heading to new concepts. Mkandla (1996) affirms that teachers are encouraged to teach even if the resources are inadequate or unavailable by improvising wherever necessary to show their knowledge of the subject matter.

\section{Importance of teaching/ learning resource}

Learning resources play an important part in education and can assist in a number of ways. Hinchliff (1992) states that learning resources can be used in providing variety in teaching and learning. They also assist retention, comprehension and capturing of attention. Mkandla (1996) states that, teaching/learning resources should facilitate learning and that they should be able to meet educational needs of the pupils.

Rwambiwa (1982) highlights that noticing how people learn and observe one picture is worth a thousand words. The visual aids help to make ideas and concepts clear. Mangal (2004) highlights that most pupils who are in the concrete stage learns quite well through the use of concrete objects. This points out how aids can supplement verbal explanation. The media could help to improve learning from verbalism to true understanding. Therefore, they could be used effectively to facilitate mastery of skills by hearing impaired pupils since most of them lack verbal communication. These resources can make the learning process simpler and enjoyable. Rwambiwa (1982) highlights that teaching aids illustrate concepts that are not readily grasped. Therefore, a school must have adequate resources for effective learning to take place.

\section{Findings}

Findings were that two participants indicated that they understood how the teachers communicated to them while eight showed that they did not understand. They indicated that there was one way communication since it was the teacher who was just dishing out the information. Students strongly suggested that there was need for their teachers to learn sign language. They felt that their teachers should improve the use of teaching aids while two participants wanted to go for field trips.

The school heads who were interviewed out that whilst all the teachers had a teaching qualification they lack the special education one. They were not qualified to teach the hearing impaired pupils. It showed that the teachers had partial knowledge on the use of sign language. They found it difficult to explain the concepts in sign language. Practical subjects teachers revealed that they could partially use sign language. They pointed out that it was not a challenge since the pupils were supposed to reproduce what they would have demonstrated.

Findings are that some teachers admitted that they heavily relied on some students who had residual hearing acting like an interpreter. Their teaching was predominantly verbal language and the interpreter could use sign language so that other pupils could benefit. Some respondents indicated that they could use sign language. However, they revealed that they sometimes fail to communicate with the pupils because they were not familiar with some signs that explained processes. Asked further about the effectiveness of the resource book they were 
using in enriching them with the necessary knowledge, responses were that, they could not follow some of the instructions form the books.

Lesson observations were carried out to see if the use of the demonstration method was properly used. Findings established that the demonstration method was not properly used. While Kim and Kellough (1996) urge the teachers to involve pupils during the demonstration, it was noted that pupil were not involved in the demonstrations. It was also noted that when the teachers were demonstrating, some pupils were standing behind others. This was violating Jarolimek's (1993) view that demonstration must take place where every pupil has full view of the operation(s) being demonstrated. After the demonstration it was also noted that there was less supervision during the lessons. Some teachers did not move around supervising pupils work as suggested by Chamberlain and Kelly (1981) suggest that finished apparel must be on display but the observations were that, there was nothing displayed. The reason for putting something on display is to give pupils an insight of what they are supposed to make. It was also noted that the IEP was not practiced in the learning sessions.

Some participants felt that use of media was inadequate whilst some felt that it was adequately used. Inconsistent data was obtained because it observed that school head was saying contradicted what the teachers have said. The teachers' documents that were observed are the schemes of work. Findings were that they were not done to meet the requirements of the IEP. The teachers were also not adhering to their schemes of work. It was also noted that teachers had stated that they were going to use the step by step demonstration during lesson delivery yet the whole process demonstration was used.

\begin{tabular}{|l|l|l|l|}
\hline \multirow{2}{*}{ SUBJECTS } & PERCENTAGE PASS RATE (\%) & \multicolumn{2}{l|}{2012} \\
\cline { 2 - 4 } & 2010 & 2011 & 45 \\
\hline Mathematics & 55 & 40 & 18 \\
\hline Science & 40 & 35 & 20 \\
\hline Geography & 35 & 30 & 75 \\
\hline Fashion and Fabrics & 65 & 80 & 80 \\
\hline Food \& Nutrition & 60 & 82 & 75 \\
\hline Woodwork & 70 & 80 & \\
\hline
\end{tabular}

Table showing $\mathrm{O}-$ Level results

The results above show that pupils did well in practical subject as compared to the academic subjects. This shows that the demonstration method proved to be effective since pupils were learning through imitation. It has reflected that the pupils were able to use their compensatory senses. Subjects like Shona, History and Bible Knowledge were not offered because they require one to have a long term memory which the disadvantaged pupils did not possess.

\section{Discussion of finding}

It was found that the teacher were not knowledgeable on the effective use of demonstration method to the hearing impaired pupils. Their documents showed that they were not fully prepared to meet the unique educational needs of each pupil. This was against Covey's (1996) view that the services for each student must be individually considered and recommended. He further suggests that, learning activities must be designed to meet specific needs of one student and that it must be truly individualized.

Although the class sizes were bearable, it was unfortunate that the teachers did not use the IEP.

Findings also revealed that some pupils were standing behind others during the demonstrations. As a result some pupils could not see properly as the teacher was demonstrating, Gwarinda (1993) suggests that teacher should ensure that every pupils has full view of the can operation being demonstrated. Therefore, pupils should be arranged in such a way that they can see properly while the teacher is demonstrating. For this to the be fully achieved, Gower, Phillips and Watters (1995) suggest that pupils should be arranged in a horse hoes format. Pupils should be arranged face to face with the teacher so that no one would obstruct the other pupils. This would enable the pupils to lip read whilst the teacher is demonstrating.

Interviews carried out revealed that the teachers were unable to fully use sign language. This had also been noted by Chiswanda in Chimedza and Peters (1994) who indicated that most teachers who are teaching the hearing impaired pupils do not know how to use sign language neither have they acquired special educating. Therefore as suggested by Zindi and Makotore (2003) the teachers need to be in-serviced, so that they are empowered to handle the classes effectively. Pupils were also not involved during the demonstrations. Three demonstrations were characterised by the teacher's dominance. However the teachers were urged by Chamberlain and Kelly (1981) to involve pupils by letting them ask questions related to the topic being 
demonstrated. Gwarinda (1993) also suggest that teachers should ensure that each pupil fully participates in carrying the operation instead of being a spectator.

Inadequate resources were also noted during the study. Pupils were sharing some equipment in their practical subjects. Chikuni (2003) affirms that each child with a handicap requires to be dealt with as an individual in order to meet the individual needs and ability. Sharing of resources resulted in students taking turns to use the resources. This hindered pupils from working at their own pace. Therefore, the school should provide adequate resources to enable pupils to at the pace that suits them best. The findings revealed that the pass rate was high to the practical subjects where demonstration method is commonly used. This highlights how the pupils used the compensatory senses in the practical subjects.

\section{Conclusions}

The study has shown that the teachers were not knowledgeable on the proper use of the demonstration method. Teachers were not involving the students. Instead they were found domineering during the lessons. The teachers were using the one- size- fit-all strategy during their lessons. It showed that Individualised Educational Plan was not respected at all. The teachers were also not in a position to use the sign language effectively. They relied on other students during their instruction. They also indicated that they could hardly sign other terminologies. Augmentation of demonstration method with other teaching methods was not properly done by the teachers. Inadequacy of teaching and learning resources was also noted. Academic achievement was seen in practical subjects as compared to the academic subjects. This reflected that pupils used their compensatory senses to produce better results.

\section{Recommendations}

Basing on the finding of this research, the following suggestions were made:

$>$ Teachers who trained at teachers' colleges and universities in special Needs Education should be recruited for they would have been trained to meet the requirements of the disadvantaged pupils.

$>$ Pupil involvement during the demonstration is of paramount importance because it enables pupils to ask questions where they are not clear.

$>$ During the demonstrations, pupil should be arranged in a horse shoe format so that no one would obstruct the other and that everyone would be in a face to face potion with the teacher to enhance lip reading.

$>$ There is need to have adequate resources so that each pupil would work at his or her own pace.

$>$ Teachers need to be in -serviced so that they acquire knowledge on how to deal with the hearing impaired children.

$>$ Teachers should involve concrete objects when they are teaching.

\section{References}

[1]. Andrusyszn, R and (1990) Teaching and Assessment: an experimental Approach. London Scrota Press.

[2]. Chamberlain, V.M. and Kelly K.M. (1981) Creative Home Economic Instruction. USA, Mac Grow Hill lank.

[3]. Chikuni, B (2003) The Teachers`Handbook. A practical approach to Teaching. Gwanda, Flame Publishers.

[4]. Child, D (1988) Psychology and the Teacher. London, Cassel press.

[5]. Chimedz a, R. M and Peterson, N.K (2003) Educational Considerations for Students with Hearing Impaired pupils, SPED 201 ZOU, Harare.

[6]. Chimedza, R and Peters, S. (1994) Disability and special needs education in African context. Harare, College Press.

[7]. Covey, S (1996) Complexities of Teaching .London, The Flamer Press.

[8]. Dean J (1986) Beginning Teaching in the Secondary School .London .Biddles Limited, Guilford\& Kings Lynn

[9]. De Young. S. (1990) Teaching Nursing Redwood City. Addison- Wesley Nursing.

[10]. Gatawa, B, S, M. (1990) The Politics of the school Curriculum: An Introduction. Harare, College Press.

[11]. Good, T.L and Brophy, J.E (1987) Looking in Classrooms. New York, Donnelley and sons Co.

[12]. Gall, M.D. Borg, R.W and Gall, J.P (1996) Educational Research: London Longman

[13]. Gower, R.Phillips. Dandy Watters, S (1995) Teaching Practice Handbook. London, Bath Press.

[14]. Gross, M.U.M. (1993) Exceptionally Gifted Children .London, Routledge. Gwanda, Flame Publishers

[15]. Hinchliff,S (1992) The Practitioner as a Teacher, London, Scutari Press. Harare, College Press.

[16]. Gwarinda, T.C. (1993) The Practice of Education .Bulawayo, R.C.P Belmont Press.

[17]. Hallahan, D.P and Kauffman, J.M (1988) Exceptional Children: Introductions to Special Education. Englewood Cliffs, Prentice Hall.

[18]. Hendrik, E. (1986) Introduction to Education Psychology. Bulawayo, College Press.

[19]. Jarolimek, J Clifford, D and Foster, S, R.(1993) Teaching and Learning in the Elementary School. New York MacMillan Publishing Company.

[20]. Jones, R.G (1990) the Principles and Practice of Education, London, Chapman and Hall.

[21]. Kasambira, K.P. (2993) Teaching Methods .Gweru, Mambo Press (Pvt) Ltd.

[22]. Kim, E.C and Kellough, R.D (1995) Resource Guide for Secondary School. USA MacMillan Publishing College.

[23]. Kudu, C.L and Tutoo, D.N Education Psychology. New Delhi, Sterling Publishers.

[24]. Linhard, N .Dlamini, N. and Barnard, W (1989). Guidance in the Classroom. Cape Town. Maskew Millerhang (Pvt) Ltd.

[25]. Mangal .S.K. Advanced Educational Psychology $2^{\text {nd }}$ Ed. India, Prentice Hall Pvt Ltd.

[26]. Marshall. And Ross man, G. (1989) Designing Qualitative Research. Newbury Park, SAGE.

[27]. McKeachie, W. (1986) Teaching Tips: A Guide for the Beginning College Teacher. Massachusetts, D. C. Heath and Company 
[28]. Meyen, E .L. (1996) Exceptional Children in Today’s `Schools 3rd Ed. USA. Love Publishing Co

[29]. Miles, J (2001) Research Methods and Statistics. London, Bell and Bain Ltd.

[30]. Mills H.R. (1991) Teaching and Training. Hong Kong, Macmillan Education Ltd.

[31]. Mkandla,V.A.(1996) Professional Studies, Getting the Job Done. Bulawayo,College Desktop.

[32]. Mutasa. N. G and Wills, G.M (1995) Modern Practice in Education and Science. Gaborone, Printing and Publishing Company.

[33]. Obanya,P. (1980) General MethodsTeaching. Lagos, Macmillan Publishers Ltd.

[34]. Petty, G.(2004)Teaching Today. 3 rd Ed London, Nelson Thornes Ltd.

[35]. Rwambiwa, J. P. T. Wikland, B. and Driscoll,J.P.(1982)Educational Technology for Schools in Developing Countries. Harare, college Press.

[36]. Smart, R(1998)Doctrines of the Great Educators. New York, St Martin's Press.

[37]. Smith, S (1986) The Visually Handicapped Children In Schools. New York,John Day Co.

[38]. Santrock, J. W. (1998) Adolescence. London, McGraw-Hill Companies.

[39]. Siyakwazi, B. J. and Syakwazi, P. D. (1999) Strategies in Teaching and Learning. Harare.Mazongororo Paper Converters.

[40]. Soroka, D. S. Hoagland, C.W. and Mohale, A.M, (1977) Micro teaching in Africa. Maseru, Mazenod Institute.

[41]. Steere,D.E. and Cavaiuolo, D.(2002)Teaching Exceptional Children . httplljournals sped .prg/EC/Archives/ vol34

[42]. UNESCO (1985),A Practical Guide to Enhance Learning, Paris, UNESCO.

[43]. Zindi, F and Makotore, S. (2000) Educational Psychology ModulePGDE303, Harare, Jongwe Printing and Publishing Company.

[44]. Zvobgo, R.J.(1990) Transforming Education. Harare. College. Press. 